\title{
BMJ Open Spatial distribution and correlates of smoking in Zambia
}

\author{
Herbert Tato Nyirenda, ${ }^{1}$ David Mulenga, ${ }^{1}$ Moono Silitongo, ${ }^{2}$ \\ Herbert BC Nyirenda, ${ }^{3}$ Tambulani Nyirenda ${ }^{4}$
}

To cite: Nyirenda HT, Mulenga D, Silitongo M, et al. Spatial distribution and correlates of smoking in Zambia. BMJ Open 2019;9:e030044. doi:10.1136/ bmjopen-2019-030044

- Prepublication history for this paper is available online. To view these files please visit the journal online (http://dx.doi org/10.1136/bmjopen-2019030044).

Received 25 February 2019 Revised 23 July 2019 Accepted 25 July 2019

Check for updates

(C) Author(s) (or their employer(s)) 2019. Re-use permitted under CC BY-NC. No commercial re-use. See rights and permissions. Published by BMJ.

${ }^{1}$ Public Health, Copperbelt University, Ndola, Zambia ${ }^{2}$ Basic Science, Copperbelt University, Ndola, Copperbelt, Zambia

${ }^{3}$ Adult and Extension Studies, University of Zambia School of Education, Lusaka, Zambia

${ }^{4}$ Public Administration,

University of Zambia School of Humanities and Social Science, Lusaka, Zambia

Correspondence to Herbert Tato Nyirenda; tatonyirenda@gmail.com

\begin{abstract}
Objective The objective of the paper was to investigate the spatial distribution and correlates of tobacco smoking in various regions of Zambia.

Methods This paper adopts a cross-sectional study design. The study used data from the 2013/2014 Zambia Demographic Health Survey which is a nationwide health survey conducted in all the 10 provinces. A random sample of men and women from 15920 households was successfully selected and interviewed. All women aged 15-49 and men aged 15-59 who were either permanent residents of the households or visitors present in the households on the night before the survey were eligible to be interviewed.
\end{abstract}

Results The results show that $8.2 \%$ and $11 \%$ of Zambians in urban and rural areas smoke, respectively. In urban areas, the risk of being a cigarette smoker was 2.31 (Cl: 1.69 to 3.16 ) and 2.03 (Cl: 1.36 to 3.02 ) times higher for the divorced and separated. However, the risk of being a cigarette smoker was lower for those with some formal education. In rural areas, the risk of being a cigarette smoker was lower for the married (relative risk ratios (RRR): $0.69, \mathrm{Cl}: 0.55$ to 0.86 ) and those with a formal education. Nevertheless, in rural areas, the risk of being a pipe and other smoker was higher for those who were self-employed (RRR: 8.46, Cl: 2.95 to 24.20 ) and with an occupation (RRR: $2.37, \mathrm{Cl}: 1.39$ to 4.02 ) but was lower among women.

Conclusion Tobacco smoking varies between and within regions as well as provinces. Therefore, interventions to curb smoking should target specific demographic, socioeconomic and cultural factors and how they are spatially distributed.

\section{INTRODUCTION}

Smoking and other forms of tobacco use can cause a wide variety of diseases and can lead to death as it is one of the common causes of preventable morbidity and mortality globally. ${ }^{12}$ Smoking is a risk factor for cardiovascular diseases, lung cancer and other forms of cancer, and it contributes to the severity of pneumonia, emphysema and chronic bronchitis symptoms. The prevalence of smoking differs widely between populations in different localities which results in disparities at national, regional and global level. ${ }^{3}$

Studies in Zambia and elsewhere have had varied findings on rural and urban disparities
Strengths and limitations of this study

The paper uses a large sample size and is nationally representative providing depths for generalisation and making inferences.

- This paper assesses the status of forms or types (cigarette, pipe and other forms) of smoking fundamental to regions of Zambia.

- The paper builds a body of knowledge on the variations in smoking hence enhancing decision-making on public health surveillance on smoking behaviour and the evaluation of policy and programme development at regional level.

- The study is limited to the available indicators hence could not associate the correlates of smoking to health outcomes such the effect of tobacco smoking on non-communicable diseases. The data could not provide other indicators/variables such as reasons for smoking as it is limited to available data.

on the influences of demographic characteristics on tobacco smoking. ${ }^{4}$ In Zambia, having a primary education decreased chances of female smoking and women living in rural areas had a threefold increased likelihood of smoking compared with those in urban areas. ${ }^{5}$ In Cameroon, Proctor et al reported no significant differences in smoking between children in rural and urban areas, but Finau et al reported significantly higher tobacco consumption in Tongan. ${ }^{6} 7$ Notably, in a report on Sub-Saharan African Countries, the greatest difference in current smoking prevalence between urban and rural areas was observed in Zambia were $22.4 \%$ in rural Zambia, compared with $6.8 \%$ in urban areas were tobacco smokers. Further, with regard to urban/rural differences, urban dwellers were more likely to be cigarette smokers while subjects living in rural areas were more often consumers of other forms of tobacco that are more accessible in these settings. ${ }^{8}$

Various Demographic Health Surveys (DHS) have shown regional variations in tobacco use. High cigarette use was reported among men in several nations of east central Africa and Madagascar and lowest use in 
nations of west central Africa, and medium use in nations of southern Africa. However, Global estimates indicate that high rates of tobacco use and tobacco-related deaths are in America and lowest in Africa. ${ }^{9}$ The burden of tobacco-related deaths in Africa revealed an increase of about $70 \%$ highest in Eastern Africa and the lowest in Central Africa. ${ }^{10}$ Findings also show that among men, the prevalence of smoking was high in Sierra Leone, Lesotho and Madagascar and low $(<10 \%)$ in Ethiopia, Benin, Ghana, Nigeria and Sao Tome \& Principe while among women, the prevalence rates were low $(<5 \%)$ in most countries except for Burundi and Sierra Leone. ${ }^{11}$ In Ghana and Lesotho, tobacco use was lower among men in urban areas compared with rural areas. ${ }^{12}$ Variations of tobacco use among men in Indonesia and among women in Nepal were also observed. ${ }^{13}$ Despite the existence of differences in tobacco use in Sub Sahara Africa, Madagascar has exceptionally higher prevalence rates almost five times higher in males than females. ${ }^{14}$ Another study indicates that tobacco use varies significantly globally for men and women as it exceeds $40 \%$ for men in all the countries examined in North Africa, West Asia, Europe, Central Asia, South and Southeast Asia. ${ }^{15}$ Age and socioeconomic status in Zambia were influential determinants of tobacco smoking. According to the 2007 Zambia Demographic Health Survey (ZDHS), the prevalence of smoking among females aged 15-49 years living in rural areas was three times higher compared with females living in urban areas. Lower education and lower socioeconomic status were also found to be a significant predictor of smoking prevalence. $^{1}$

It is vital to assess rural-urban differentials in tobacco smoking as Zambia is a land-locked country that has administratively been divided into 10 provinces of which two are predominantly urban and the remaining eight are predominantly rural. The country has a mixed economy consisting of a rural agricultural sector and a modern urban sector that, geographically, follows the rail line. Poverty continued to be more prevalent among rural than urban residents. ${ }^{1}$ The paper was aimed at estimating correlates of tobacco smoking among rural and urban Zambians. Understanding the correlates of smoking in rural and urban areas can contribute to filling the gap on how to deal with non-communicable diseases (NCDs) which generally develop over a long period and, if addressed at an early stage, are often preventable. ${ }^{10}$

\section{METHODS}

\section{Population characteristics and setting}

Zambia covers a land area of $752612 \mathrm{~km}^{2}$. This study was conducted in Zambia's 10 provinces. The provinces include Central, Copperbelt, Eastern, Lusaka, Southern, Luapula, Muchinga, Northern, North-Western and Western provinces.

\section{Data source}

This paper used data from the $2013 / 2014$ ZDHS which is a nationally representative sample survey of women and men of reproductive age designed to provide up-to-date information on health status and behaviour. This study adopted a cross-sectional study design. The study was purely quantitative and was conducted through structured interviews. Three questionnaires were used and these include; the Household Questionnaire, the Woman's Questionnaire and the Man's Questionnaire. The three instruments were based on the questionnaires developed by the Demographic and Health Surveys Program and adapted to Zambia's specific data needs.

The 2013-2014 ZDHS used an updated list of enumeration areas (EAs) for the 2010 Population and Housing Census as the sampling frame for the survey. The frame comprised 25631 EAs and 2815897 households. An EA is a convenient geographical area with an average size of 130 households or 600 people. For each EA, information is available on its location, type of residence (rural or urban), number of households and total population. Each EA has a cartographical map with delimited boundaries and main landmarks of the area. A 2013-2014 ZDHS cluster is essentially representative of an EA.

The survey used a two-stage stratified cluster sample design, with EAs (or clusters) selected during the first stage and households selected during the second stage. In the first stage, 722 EAs (305 in urban areas and 417 in rural areas) were selected with probability proportional to the size. The 10 provinces were stratified into 20 sampling strata and a complete list of households served as the sampling frame in the selection of households for enumeration with an average of 25 households being selected in each EA. Therefore, a random sample of 18052 households across Zambia was selected from 722 clusters, of which only 16258 were occupied at the time of the fieldwork. Of the occupied households, 15920 were successfully interviewed, yielding a household response rate of 98\%. 'All women aged 15-49 and men aged 15-59 who were either permanent residents of the households or visitors present in the households on the night before the survey were eligible to be interviewed', (2013/2014, ZDHS).

\section{Measurement and definition}

\section{Dependent variable}

Smoking in this paper refers to the act or habit of inhaling and exhaling the smoke of tobacco by men and women in rural and urban Zambia. Therefore, tobacco use status is a composite variable from the various questions on the mode of tobacco smoking and was classified into three categories namely non-smoker, cigarette smoker, and lastly pipe and other smokers. The variable was thus measured on a nominal scale.

\section{Independent variables}

The independent variables include respondent's age, province, region, years lived in place of residence, highest 
educational level, religion, wealth index, marital status, gender, occupation, sex of the household head, frequency of listening to radio and television and relationship to the household head.

The wealth index is a composite measure of a household's cumulative living standard and was calculated using easy-to-collect data on a household's ownership of selected assets, such as televisions and bicycles, materials used for housing construction and types of water access and sanitation facilities. The wealth index was thus generated with a statistical procedure known as principal components analysis, the wealth index places individual households on a continuous scale of relative wealth. DHS classified households into five wealth quintiles which are lowest, second, middle, fourth and highest. This study classified the wealth index into three categories as follows: lowest and second as low, middle as middle, fourth and highest as high.

\section{Data analysis}

Data analysis was done using Stata V.13 and the data was survey weighted to factor in population estimates. Bivariate analysis or Chi-square $\left(\chi^{2}\right)$ analysis was conducted in an attempt to describe and establish the association between smoking and socioeconomic as well as demographic factors. A multivariate analysis involving multinomial logistic regression was conducted to ascertain the risk associated with smoking. Therefore, Relative Risk Ratios (RRR) associated with smoking were generated for the socioeconomic and demographic factors that were significant at bivariate analysis $\left(\chi^{2}\right)$. The study also conducted a spatial distribution analysis indicating the regional differences in tobacco smoking and Moran's I to ascertain autocorrelation

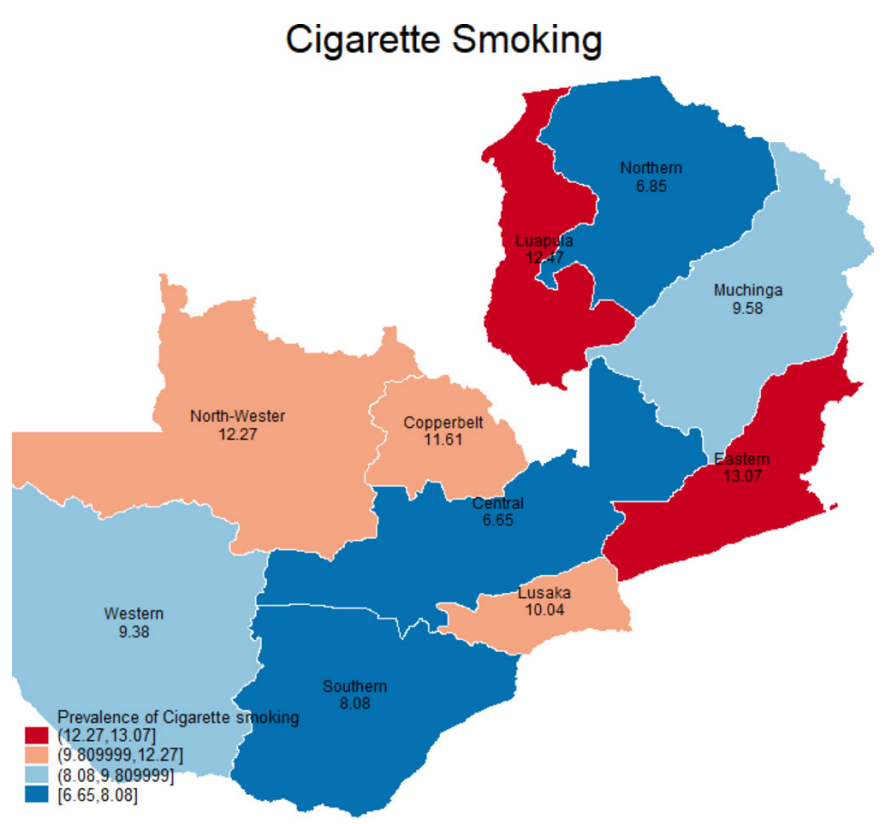

Figure 1 Spatial distribution of cigarette smoking by Province.

\section{Patient and public involvement}

This was a household survey which involved the participation of the general public. Participants are made aware of the study results through publication and statistical bulletins. There were no patients involved in the study.

\section{Ethical consideration}

The paper used secondary data hence posed no risk or harm to the respondents. The data did not contain any of the respondent's names nor traces of the respondents. This paper, therefore, holds respondents' information with the highest confidentiality.

\section{RESULTS \\ Socioeconomic and demographic characteristics}

The results reveal that $46.1 \%$ of Zambians live in urban areas while $53.9 \%$ live in rural areas. In the urban area, $22.6 \%$ of the study participants were aged between 15 and 19 years. Almost half $(49.1 \%)$ were married, about 6 in $10(59.2 \%)$ had a secondary school education, over half $(52.7 \%)$ were females, over three quarters $(78.4 \%)$ were protestants, $85.8 \%$ were in the high wealth quintile, 4 in $10(40.6 \%)$ were not working, $45.4 \%$ listened to the radio almost every day and 6 in $10(60.4 \%)$ watched television almost every day, $31 \%$ were the household heads and over three quarters $(78.1 \%)$ of the households were male-headed households.

In the rural area, $22.1 \%$ of the study participants were aged between 15 and 19 years. Close to two-thirds (64\%) were married, over half $(58.2 \%)$ had a primary school education, slightly over half $(52.5 \%)$ were females, about 8 in $10(80.3 \%)$ were protestants, $61.1 \%$ were in the low wealth quintile, over one-third $(36.5 \%)$ were employed in the agriculture sector, $36.5 \%$ never listened to the radio and almost three quarters $(72.4 \%)$ never watched television, over one-third were $(35.5 \%)$ were household heads and 8 in $10(81.1 \%)$ of the households were male-headed households.

\section{Prevalence of smoking}

The results show that only $8.2 \%$ of Zambians in urban areas smoke. However, $8.1 \%$ were cigarette smokers and only $0.1 \%$ smoked pipe and other. With regard to gender, $16.7 \%$ of the males smoked cigarette compared with only $0.3 \%$ of females.

Results also showed that $11 \%$ of Zambians in rural areas smoke. One in $10(10.7 \%)$ were cigarette smokers and only $0.3 \%$ smoked pipe and other. With regards to gender, $21.8 \%$ of the males smoked cigarette compared with only $0.6 \%$ of females

\section{Spatial distribution of cigarette smoking}

Figure 1 shows the spatial distribution of cigarette smoking in Zambia. The prevalence of cigarette smoking was highest in Eastern and Luapula provinces and lowest in Western and Muchinga provinces in Zambia. After running the Moran's I to assess for autocorrelation, the 


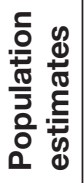

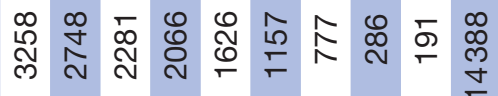

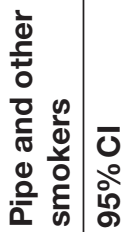

กิ ติ

$\begin{array}{lll}0 & 0 \\ 0 & 0 & 0 \\ 0 & 0 & 0\end{array}$

¿.

สุ

운

은 है ตั

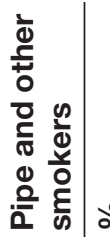

กิ

†ே

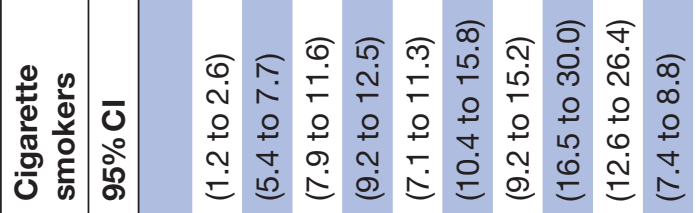

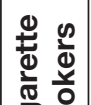

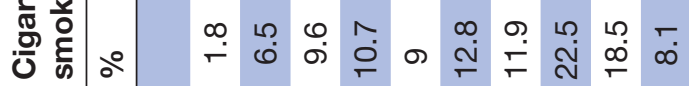

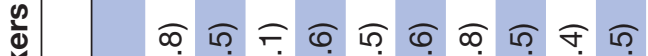

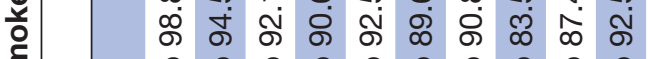

ติ

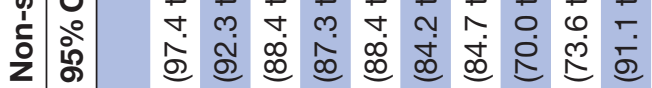

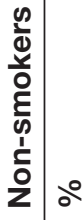

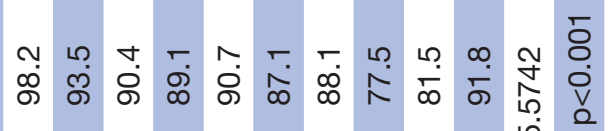

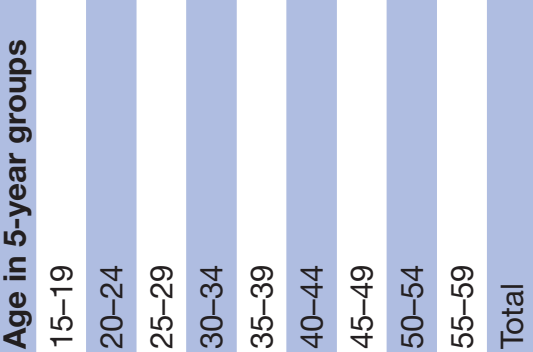

每

垔

응

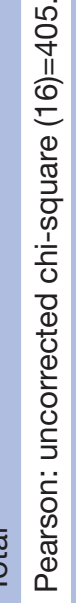

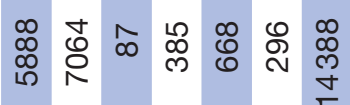

先管

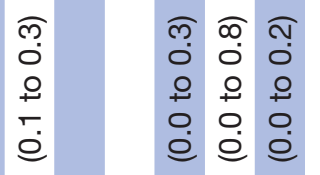

б. ซิ

$+ㅇ+2$ 우

이 웅 웅

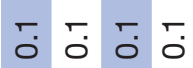

$$
\text { б. }
$$

ơ ণิ

$\begin{array}{lllllll}1 & 1 & \overline{1} & 0 & 1 & 0 & \infty \\ 0 & 0 & 0 & 0 & 0 & 0 & 0 \\ +1 & 0 & 0 & 0\end{array}$

ஸָ

बढ़

0 일

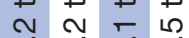

மอ ஹ่ மீ

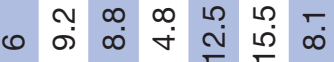

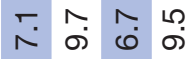

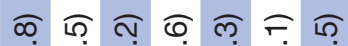

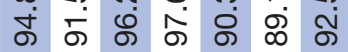

웅ㅇㅇㅇㅇㅇㅇㅇ

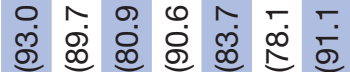

ㄷำ $\widehat{\operatorname{T}}$

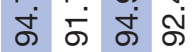

우 우 우오

$m$ in 50

வ

ব

$\infty$ ก

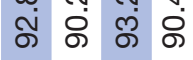

8 v

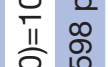

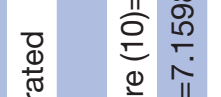

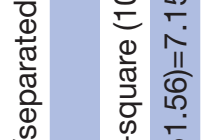

ब⿳亠口冋.

焉

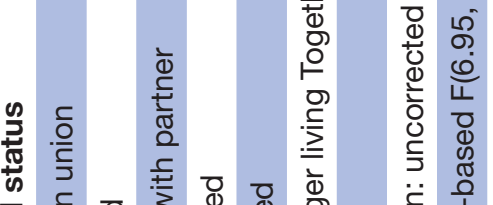

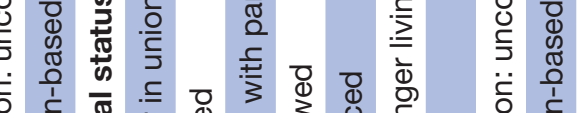

䍃 


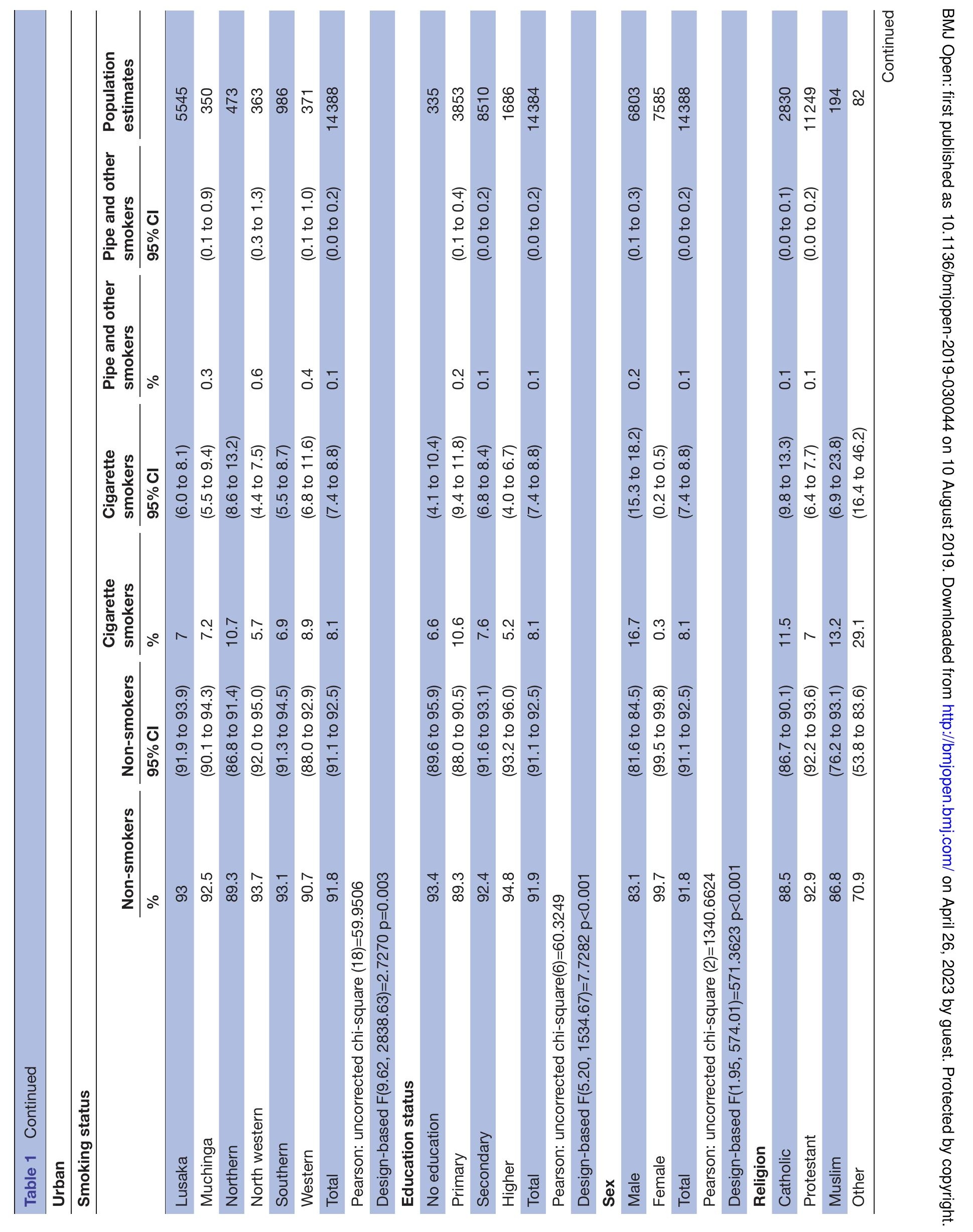




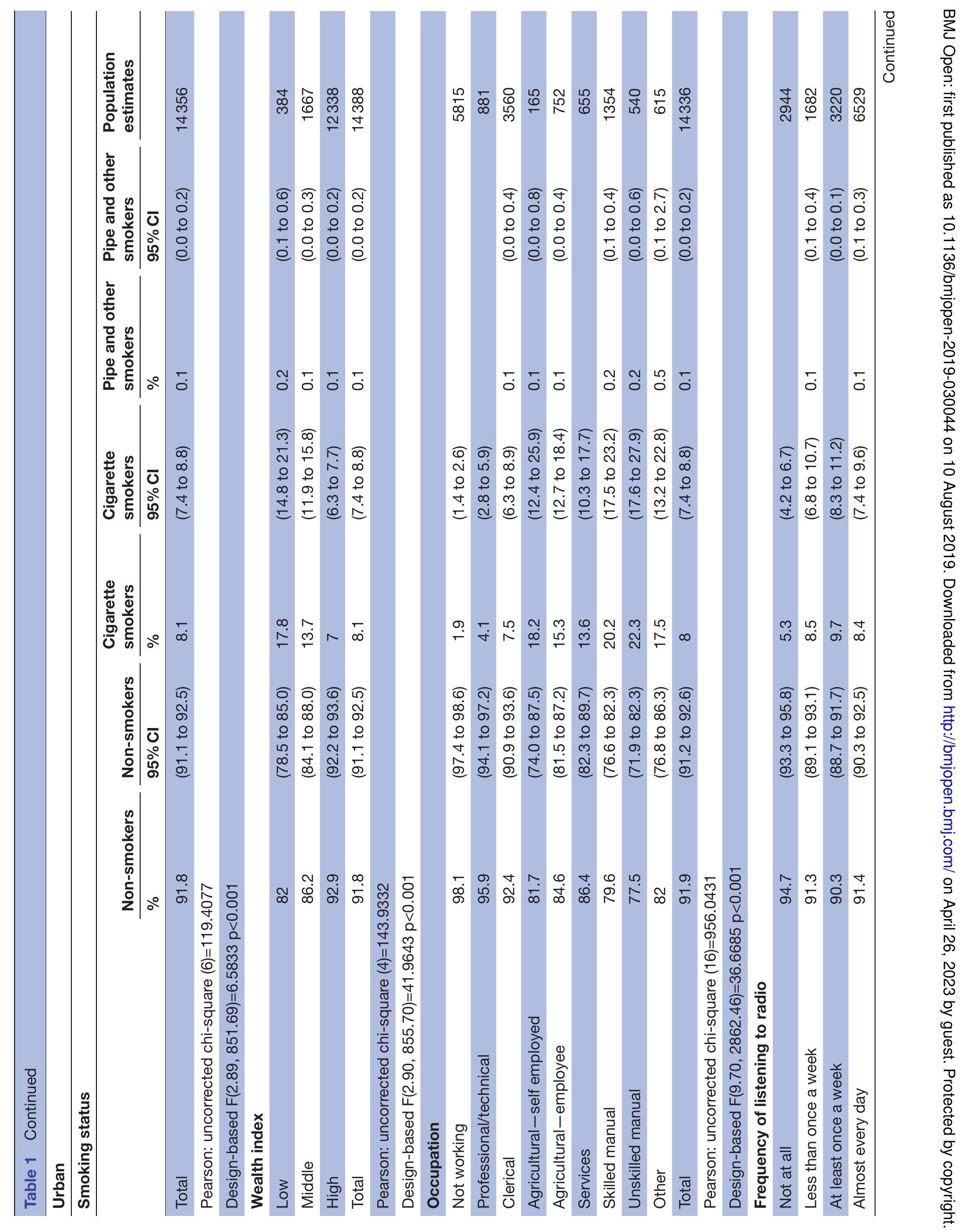




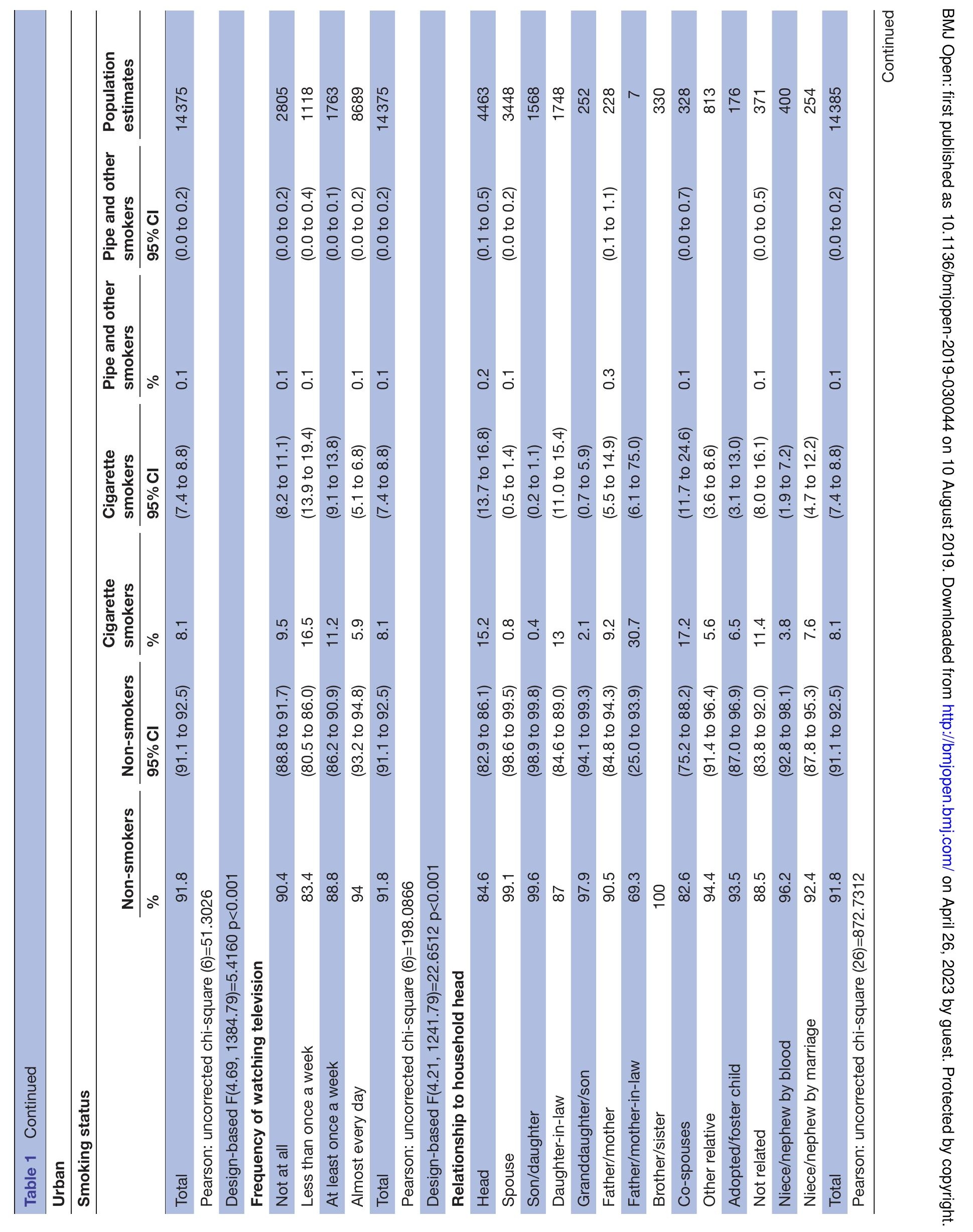




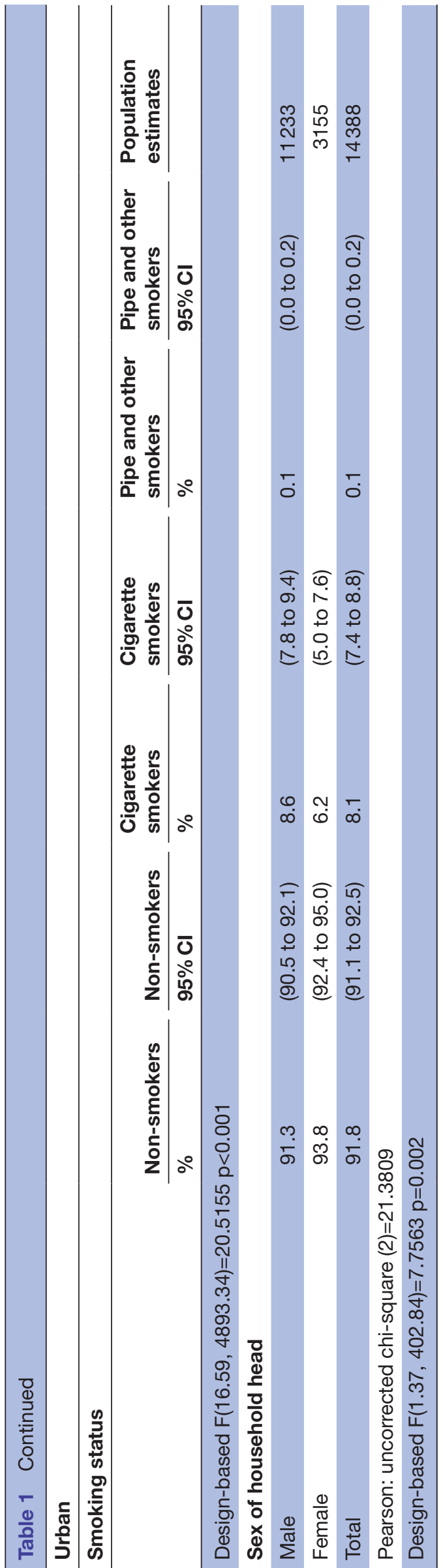

results show that there was clustering of dissimilar values in tobacco use among province. However the results were not statistically significant $(\mathrm{p}=0.152)$.

\section{$\chi^{2}$ : association between smoking and socioeconomic and demographic factors}

The $\chi^{2}$ results indicate that among residents in urban areas, a statistically significant association existed between smoking status and the following factors: age $(\mathrm{p}<0.001)$, marital status $(\mathrm{p}<0.001)$, province $(\mathrm{p}=0.003)$, education status $(p<0.001)$, sex $(p<0.001)$, religion $(p<0.001)$, wealth index $(\mathrm{p}<0.001)$, occupation $(\mathrm{p}<0.001)$, frequency of listening to the radio $(\mathrm{p}<0.001)$ and watching television $(p<0.001)$, respondents relationship to the household head $(\mathrm{p}<0.001)$ and sex of the household head $(\mathrm{p}=0.002) \quad($ table 1$)$.

A statistically significant association was found between smoking status and the following factors among rural residents; age $(\mathrm{p}<0.001)$, marital status $(\mathrm{p}<0.001)$, province $(p<0.001)$, education status $(p<0.001)$, sex $(p<0.001)$, religion $(\mathrm{p}<0.001)$, wealth index $(\mathrm{p}<0.001)$, occupation $(p<0.001)$, frequency of listening to the radio $(p<0.001)$ and watching television $(\mathrm{p}<0.001)$, respondents relationship to the household head $(\mathrm{p}<0.001)$ and sex of the household head $(\mathrm{p}<0.001)$ (table 2$)$.

\section{Spearman Rank Correlation}

A Spearman rank correlation was performed between age and wealth index, the findings indicate a statistically significant weak negative correlation $(r=-0.0668$, $\mathrm{p}<0.001$ ) between age and wealth index.

Multinomial Logistic regression: Correlates of smoking in rural and urban Zambia (RRR).

The results are split into two tables, table 3 presenting results of multinomial logistic regression for cigarette smokers while table 4 presenting results of the multinomial logistic regression for pipe and other smokers. After conducting a multinomial logistic regression and controlling for predictor variables, results in table 3 show that the relative risk of being a cigarette smoker versus a non-smoker increases with each additional age group in both urban and rural areas. For residents in urban areas, the risk of being a cigarette smoker was 3.44 (CI: 1.48 to 7.96), 1.55 (CI: 1.25 to 1.93 ) and 2.08 (CI: 1.24 to 3.49 ) times higher for sons/daughters, son/daughter-in-law and niece/nephew by marriage to the household head relative to the head of the household, respectively, while in rural areas the risk was 0.66 (CI: 0.51 to 0.85 ) and 0.49 (CI: 0.26 to 0.89 ) lower for son/daughter-in-law and others related to the household head, respectively.

Similarly in urban areas, the risk of being a cigarette smoker versus a non-smoker was 2.31 (CI: 1.69 to 3.16) and 2.03 (CI: 1.36 to 3.02) times higher for the divorced and separated relative to the never married respectively were as in rural areas the risk was lower for the married (RRR: 0.69 , CI: 0.55 to 0.86 ) and those living with a partner (RRR: 0.45, CI: 0.23 to 0.90 ) relative to the never married. Further, the risk of being a cigarette smoker 


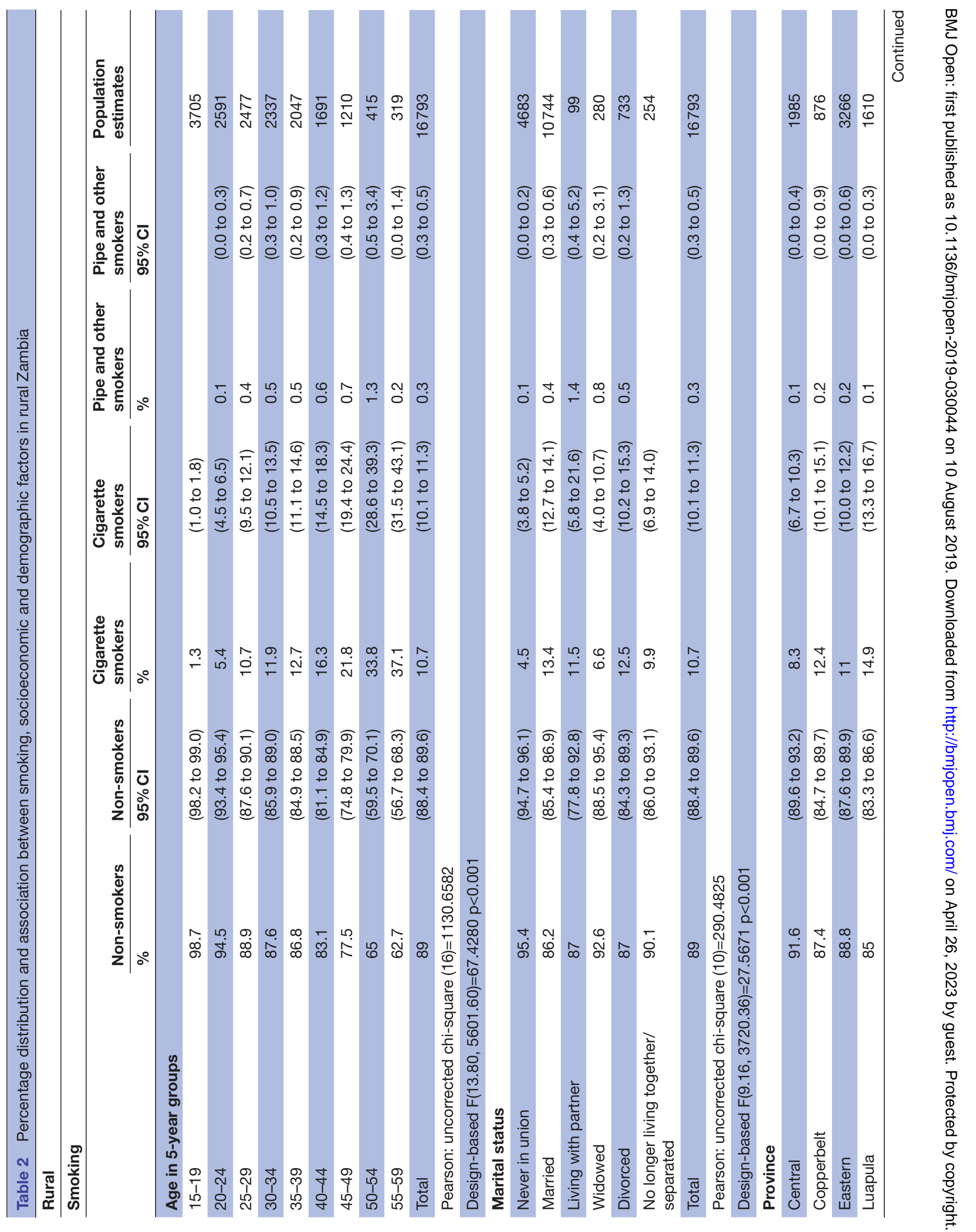




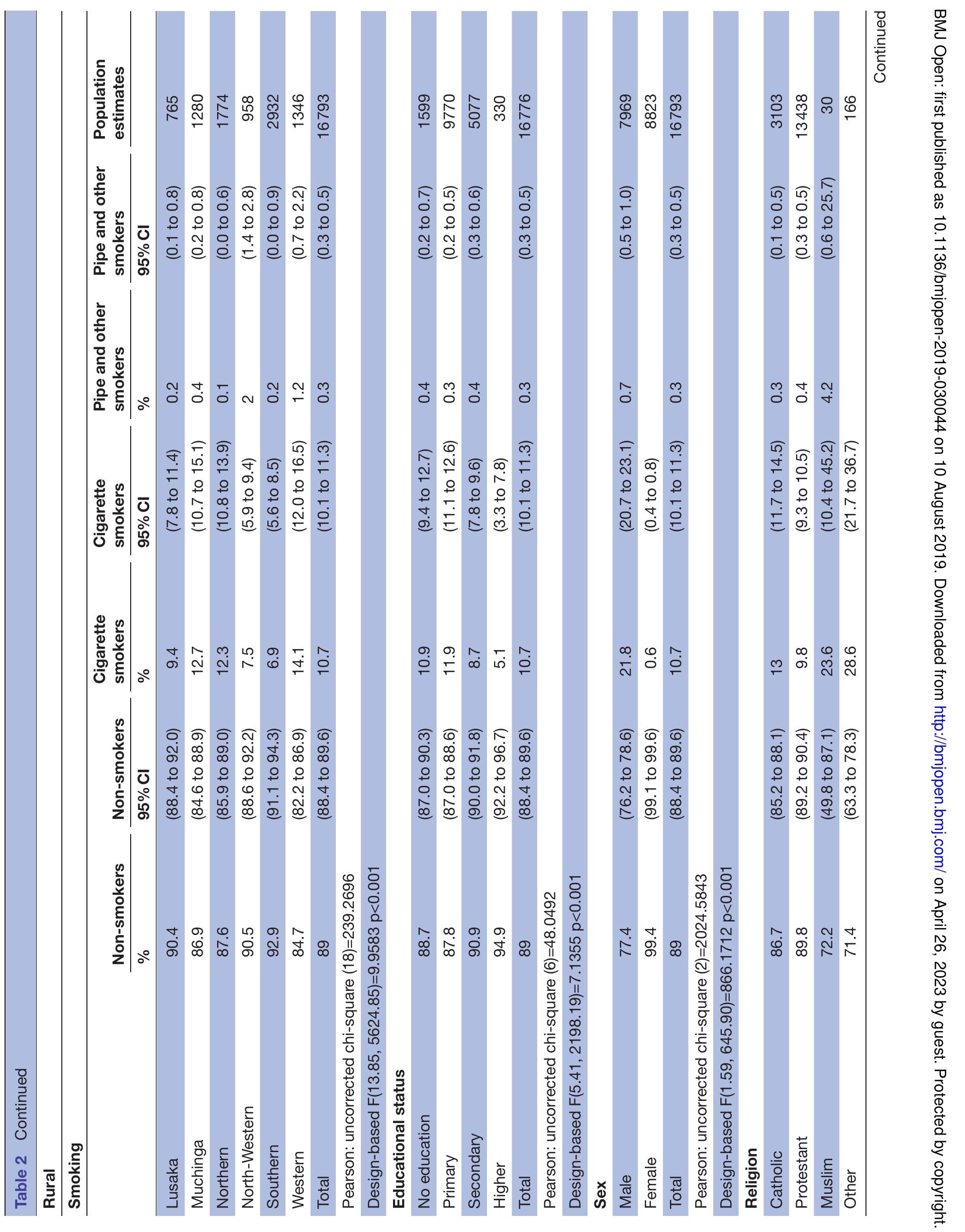




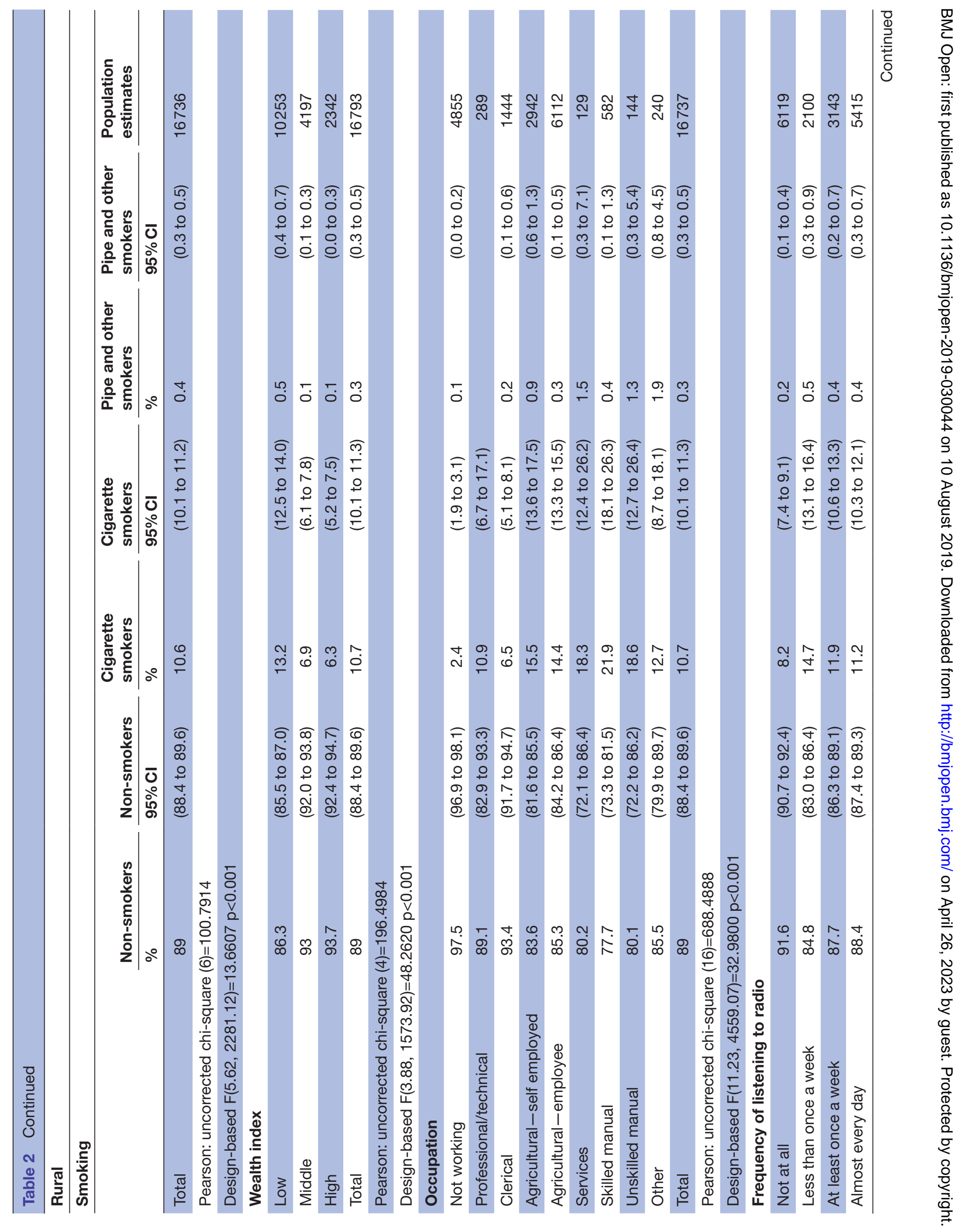




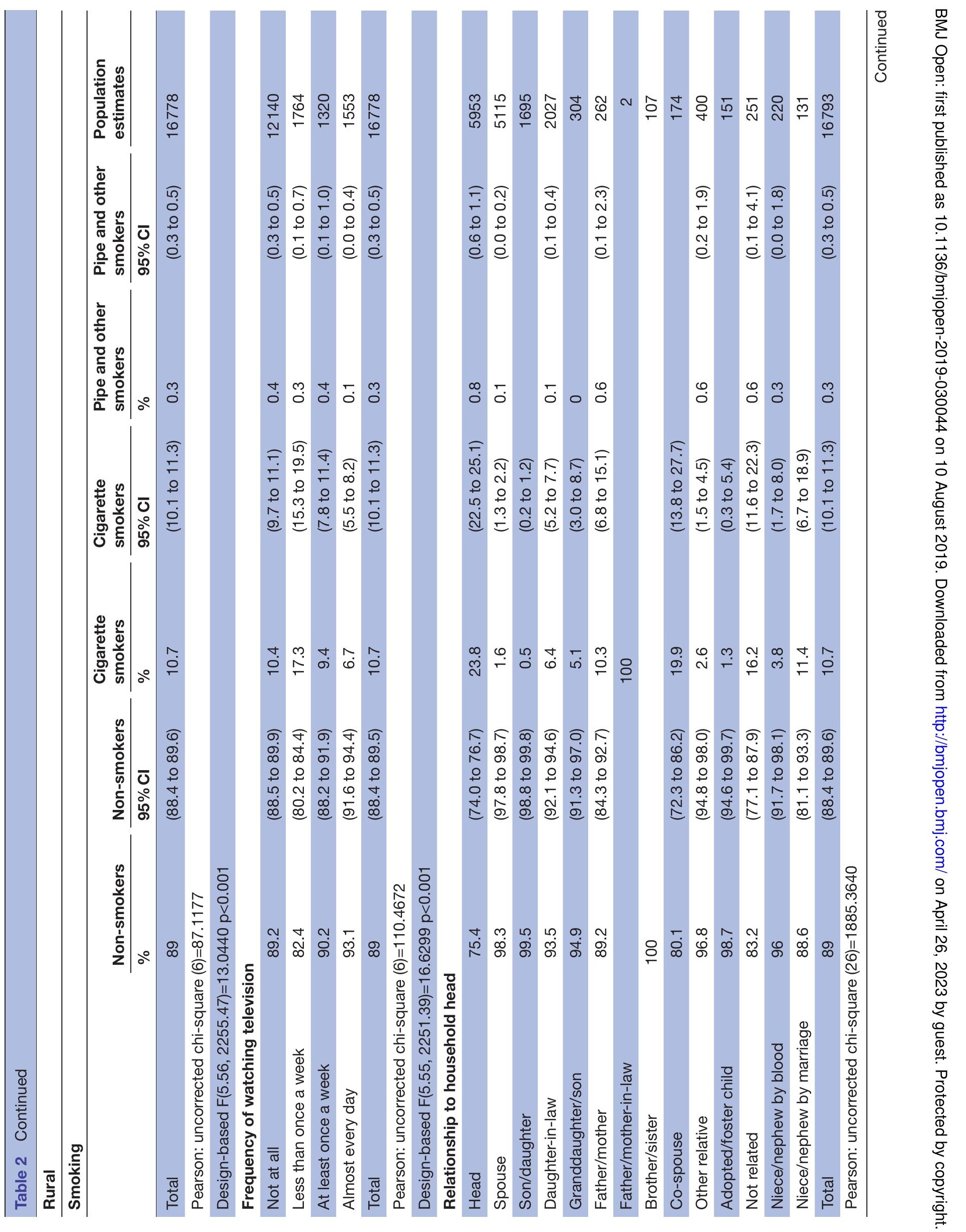




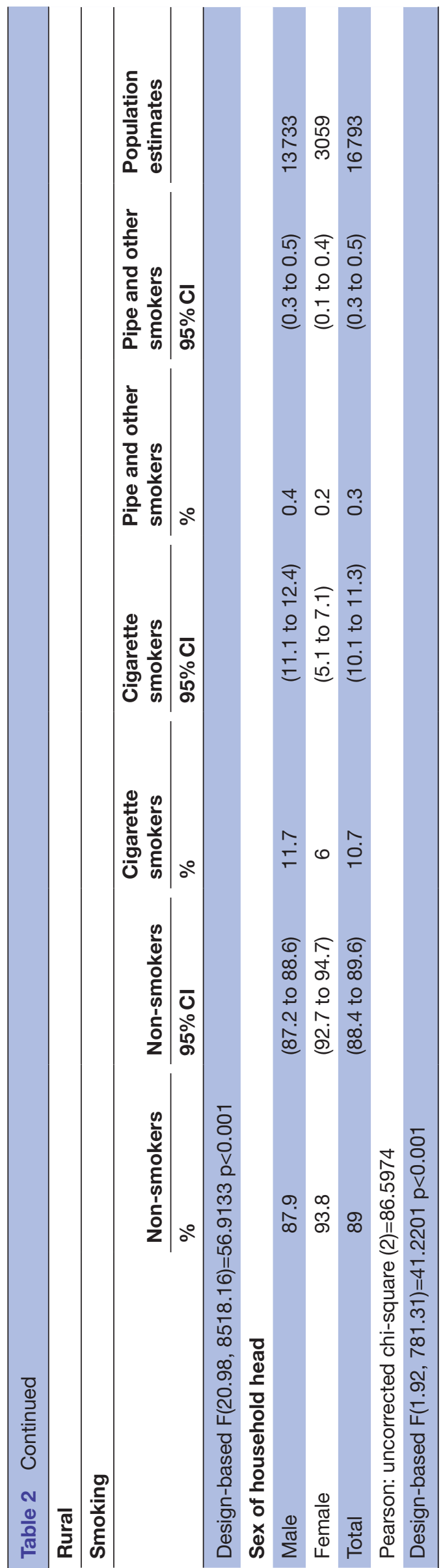

versus a non-smoker for urban residents was higher for those working or with an occupation relative to those who were not doing anything. On the contrary, the risk of being a cigarette smoker versus a non-smoker in both urban and rural was lower for the following: those with an education relative to those with no form of education; Protestants relative to Catholics and lastly those in the middle wealth quintile as well as high wealth quintile relative to those in the low wealth quintile.

On the other hand, table 4 shows that the risk of being a pipe and other smoker versus a non-smoker increases with each additional age in rural areas. In urban areas, the risk of being a pipe and other smoker was higher for fathers/mothers to the household head (RRR: 14.29, CI: 1.66 to 122.79$)$ relative to the head of the household. Similarly, in rural areas, the risk of being a pipe and other smoker was higher for those who were self-employed (RRR: 8.46, CI: 2.95 to 24.20 ) or with an occupation (RRR: 2.37, CI: 1.39 to 4.02 ) relative to those who were not doing anything and was higher for Muslims (RRR: 18.55, CI: 1.81 to 189.77 ) relatives to Catholics.

Conversely, in urban areas, the risk of being a pipe and other smoker was lower for those with a primary education (RRR: 0.36, CI: 0.11 to 1.16 ) relative to those without any form of education; and for protestants (RRR: 0.39, CI: 0.14 to 1.11 ) relative to Catholics. Similarly, in rural areas, the risk of being a pipe and other smoker was lower for those in the middle wealth quintile (RRR: 0.31, CI: 0.14 to 0.67 ) and high wealth quintile (RRR: 0.16, CI: 0.04 to 0.73 ) relative to those in the low wealth quintile. However, in both urban and rural, the risk of being a pipe and other smoker was lower for women relative to men.

\section{DISCUSSION}

The findings of this study indicate that the prevalence of smoking in Zambia is a notable public health problem and it is consistent with the prevailing prevalence in Sub-Saharan Africa. ${ }^{9}$ The overall prevalence of smoking in this study is slightly higher in the overall urban Zambia compared with the prevalence obtained in Lusaka alone, the capital city of Zambia by Siziya et al. ${ }^{16}$ The findings are similar to findings by Pampel who found high cigarette use among urban residents. ${ }^{9}$ The prevalence of male cigarette smokers in this study was high compared with that of females both in the rural and urban areas. This is consistent with the findings of Siziya et al in Lusaka ${ }^{16}$ and of Zyaambo et al in Kitwe, the mining city of Zambia ${ }^{17}$ and of Mulenga $e t$ al in Kaoma and Kasama, rural towns in Zambia. ${ }^{18}$ To the best of our knowledge, the current study is the first of its kind to evaluate and compare smoking between rural and urban in the same study in Zambia, the other studies only focused on either rural or urban areas alone.

In many previous studies, the risk of cigarette smoking has been correlated to various demographic, socioeconomic and cultural factors by different researchers. Our study found that; age, gender, education, occupation, 
Table 3 Correlates of cigarette smoking in rural and urban Zambia-multinomial logistic regression (RRR)

Urban Rural

RRR

\begin{tabular}{|c|c|c|c|}
\hline Base outcome & \multicolumn{3}{|l|}{ Non-smokers } \\
\hline Type of smoking & \multicolumn{3}{|l|}{ Cigarette smokers } \\
\hline \multicolumn{4}{|l|}{$\begin{array}{l}\text { Socioeconomic and demographic } \\
\text { variables }\end{array}$} \\
\hline \multirow{17}{*}{ Age } & 15-19 (RC) & 1 & 1 \\
\hline & $20-24$ & $4.33^{\star \star \star}$ & $5.77^{\star \star \star}$ \\
\hline & & (3.08-6.09) & $(4.08-8.15)$ \\
\hline & $25-29$ & $9.27^{\star \star \star}$ & $12.97^{\star \star \star}$ \\
\hline & & $(6.51-13.22)$ & $(9.00-18.68)$ \\
\hline & $30-34$ & $9.16^{\star \star \star}$ & $13.82^{\star \star \star}$ \\
\hline & & $(6.3-13.2)$ & $(9.47-20.16)$ \\
\hline & $35-39$ & $7.71^{\star \star \star}$ & $15.21^{\star * \star}$ \\
\hline & & $(5.28-11.25)$ & $(10.38-22.28)$ \\
\hline & $40-44$ & $9.95^{\star \star \star}$ & $19.96^{\star \star \star}$ \\
\hline & & $(6.75-14.67)$ & $(13.63-29.25)$ \\
\hline & $45-49$ & $10.96^{\star \star \star}$ & $28.52^{\star \star \star}$ \\
\hline & & $(7.28-16.51)$ & $(19.31-42.13)$ \\
\hline & $50-54$ & $8.96^{\star \star \star}$ & $22.00^{\star \star \star}$ \\
\hline & & $(5.78-13.91)$ & $(14.56-33.25)$ \\
\hline & $55-59$ & $10.93^{\star \star \star}$ & $20.17^{\star \star \star}$ \\
\hline & & $(6.76-17.67)$ & $(13.15-30.93)$ \\
\hline \multirow[t]{9}{*}{ Relationship to the household head } & Head (RC) & 1 & 1 \\
\hline & Son/daughter & $3.44^{\star \star \star}$ & \\
\hline & & $(1.48-7.96)$ & \\
\hline & Son/daughter-in-law & $1.55^{\star \star \star}$ & $0.66^{\star \star \star}$ \\
\hline & & $(1.25-1.93)$ & $(0.51-0.85)$ \\
\hline & Niece/nephew by marriage & $2.08^{\star \star \star}$ & \\
\hline & & $(1.24-3.49)$ & \\
\hline & Other relative & & $0.49^{\star \star}$ \\
\hline & & & $(0.26-0.89)$ \\
\hline \multirow[t]{9}{*}{ Marital status } & Never in union (RC) & & 1 \\
\hline & Married & & $0.69^{\star \star \star}$ \\
\hline & & & $(0.55-0.86)$ \\
\hline & Living with a partner & & $0.45^{\star \star}$ \\
\hline & & & $(0.23-0.90)$ \\
\hline & Divorced & $2.31^{\star \star \star}$ & $1.84^{\star \star \star}$ \\
\hline & & (1.69-3.16) & $(1.30-2.61)$ \\
\hline & No longer living together/separated & $2.03^{\star \star \star}$ & \\
\hline & & $(1.36-3.02)$ & \\
\hline
\end{tabular}

Continued 
Table 3 Continued

Urban Rural

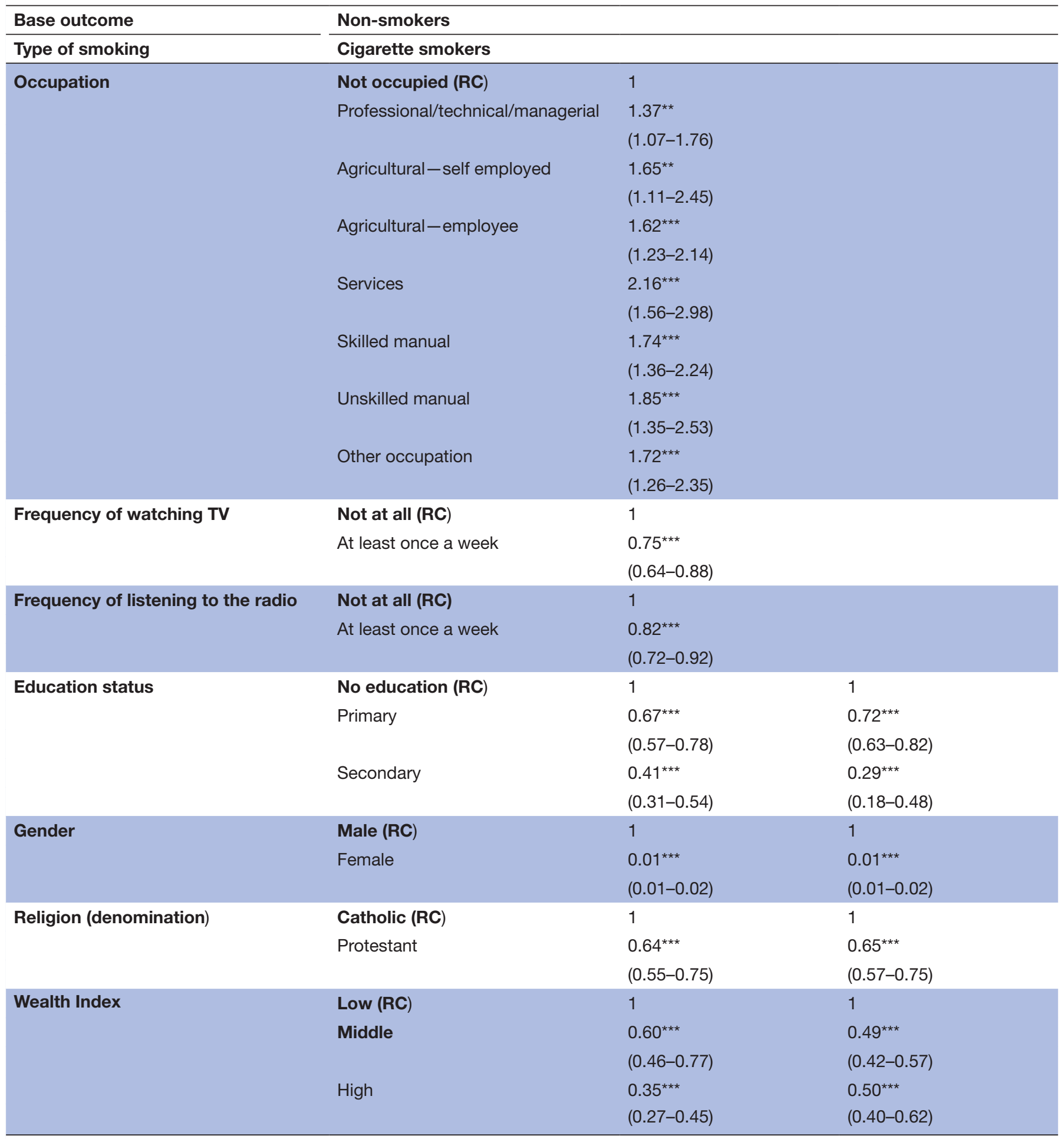

$\mathrm{Cl}$ in parentheses.

*** $p<0.01,{ }^{* \star} p<0.05$.

$+p<0.1$.

$\mathrm{RC}$, reference category; RRR, relative risk ratio; $\mathrm{TV}$, television. 
Table 4 Correlates of smoking in rural and urban Zambia-multinomial logistic regression (RRR)

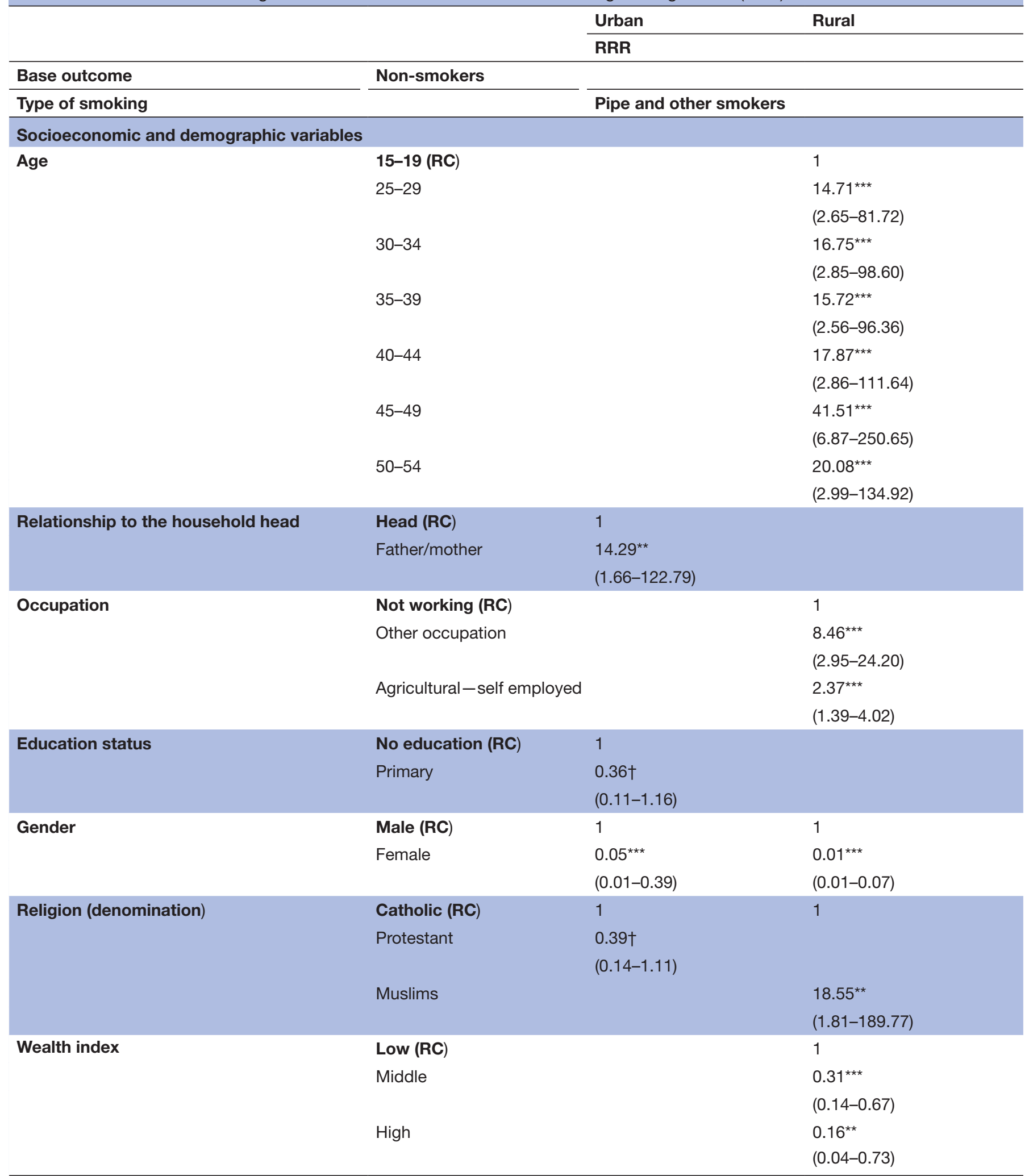

$\mathrm{Cl}$ in parentheses,

${ }^{* * *} \mathrm{p}<0.01,{ }^{\star *} \mathrm{p}<0.05$.

$+p<0.1$

$\mathrm{RC}$, reference category.; RRR, relative risk ratio. 
marital status, religion, wealth index, relationship to head of household, frequency of watching television and listening to the radio are significantly associated with the risk of being a cigarette smoker. This study documents a significant association between age and the risk of cigarette smoking both in the rural and urban areas of Zambia. The observation by our study is that the risk of being a cigarette smoker in both rural and urban area increases with the increase in age. The findings concur with findings by Sreeramareddy et al who found that older ages were strongly associated with smoking. ${ }^{11}$ Similar findings were found by Mamudu in Madagascar indicating that age, education, wealth, employment, marriage, religion and place of residence as factors significantly associated with the choice of tobacco use among males, while age, wealth and employment were significantly associated with that of females. ${ }^{14}$ This stands in contrast with the finding by Townsend and colleagues who relate age to ability to afford the cost of cigarette as opposed to simply increase in age. ${ }^{19}$

Gender showed significant association with the risk of cigarette smoking in our study, females presented a reduced risk of cigarette smoking compared with males and this is in accord with what is obtaining in sub-Saharan Africa where the estimated prevalence of tobacco consumption is $14 \%$ in males and $2 \%$ in females in $2010 .{ }^{16}$ Similarly, another study conducted in the rural parts of Zambia, Kaoma and Kasama by Mulenga et al indicate a high prevalence of smoking at $39.6 \%$ among males and $10.8 \%$ among female and $40.4 \%$ among males and $7.2 \%$ among females respectively. ${ }^{20}$ Pampel also found that women had much lower prevalence than men but similar social patterns of use. ${ }^{9}$ Similarly, a study by Sreeramareddy et al found that there were fewer females who smoked in most countries. ${ }^{11}$ However, a study by Kwamena in Ghana and Lesotho showed that Smoking prevalence was smaller in men with higher level of education compared with men with no education. ${ }^{12}$ According to Hsia and Kaufmann, low tobacco use in men is generally found in countries in sub-Saharan Africa and Latin America/Caribbean while women are less likely than men to use tobacco. ${ }^{15}$

In our study religion was significantly associated with cigarette smoking. Non-Catholics were at low risk of cigarette smoking compared with catholic participants. This is supported by the religion-based public health interventions: relevance for tobacco control by Jabbour and Fouad. ${ }^{21}$ Religious affiliation was also noted by Kwamena, who found that tobacco use was higher in men who are traditionalist/spiritualists or who had no religion compared with Christians. ${ }^{12}$

Compared with those in the low wealth index, those in the middle and high wealth index were at a reduced risk of cigarette smoking. This findings are in contrast with the findings of Townsend and colleagues. ${ }^{19}$ On the other hand, individuals with an occupation in our study were at an increased risk of being cigarette smokers compared with those not having a job. This aspect agrees with Townsend who states that those with an income are less responsive to the health information and promotion regarding tobacco smoking. According to Kwamena, tobacco use was lower among professional workers compared with men in the agricultural sector in both Ghana and Lesotho. ${ }^{12}$

Individuals in this study from the rural areas were at an increased risk of cigarette smoking compared with those from the urban areas. This finding is comparable with the findings in Tunisia by Fakhfakf $e t a l^{22}$ who also observed a higher prevalence of smoking in the rural area compared with the urban areas. It is also important to note that the prevalence of cigarette smoking in $2014^{19}$ is consistent with the prevalence obtained in previous ZDHS cigarette smoking statistics.

Our findings show that those with primary and secondary education were at a lower risk of cigarette smoking compared with those with no form of education, similarly, individuals who watched television or listened to the radio at least once a week were at a reduced risk of cigarette smoking compared with those who never watched television or listened to radio at all. The study findings also correlate with findings by Pampel who found that the less educated and lower status workers had high cigarette use. ${ }^{9}$ This observation is vital for programming and interventions as documented by Chapman ${ }^{23}$ stating that there is evidence that health information, promotion, advertising and smoking restrictions can be effective interventions of cigarette smoking on television and radio.

Relatives to the head of household in urban areas were at a higher risk of smoking cigarette compared with the head of household. This finding agrees with the results in Chongwe, Zambia and Nigeria where the adolescents whose parents were smokers were more likely to start smoking ${ }^{24}$ compared with individuals whose parents were not smokers. However, in rural areas, our results indicate that relatives to the head of household were at low risk of smoking compared with the head of household and this can be attributed to local customs, implying some form of respect for the head of household. The married/ living with a partner were at a lower risk of smoking cigarette compared with those who have never been in union before. On the contrary, the divorced/separated were at a higher risk of smoking cigarette compared with those who have never been in union both in rural and urban area. This is more likely to be attributed to ways of reducing stress and feeling loneliness. The study was limited to the available indicators in the DHS dataset hence could not associate the correlates of smoking to health outcomes as tobacco use is a risk factor to many NCDs.

\section{CONCLUSION}

Factors influencing tobacco smoking vary between and within regions as well as provinces. The geographic disparities play a role in tobacco consumption between rural and urban areas. Therefore, interventions to curb smoking should target specific demographic, socioeconomic and cultural factors. 
Acknowledgements We wish to thank the Zambia Central Statistics Office (CSO) for granting us permission to use the data. More specifically, we thank the Dissemination Office for the quick response to the request.

Contributors All authors were responsible for facets of the study. However, HTN was responsible for the formulation, methods, data analysis, results and discussion of the study. DM and TN contributed to the design, formulation and study discussion. HBCN and MS contributed to all facets of this research including writing, proof reading and discussion. The paper was read and reviewed by all authors read. Funding The study was not funded as it used National Demographic Health Survey data.

Map disclaimer The depiction of boundaries on the map(s) in this article do not imply the expression of any opinion whatsoever on the part of BMJ (or any member of its group) concerning the legal status of any country, territory, jurisdiction or area or of its authorities. The map(s) are provided without any warranty of any kind, either express or implied.

Competing interests None declared.

Patient consent for publication Not required.

Ethics approval Permission to use the data was sought from Central Statistics Office, Zambia and approval to use the data was granted.

Provenance and peer review Not commissioned; externally peer reviewed.

Data availability statement Data are available in a public, open access repository. Data are available upon reasonable request.

Open access This is an open access article distributed in accordance with the Creative Commons Attribution Non Commercial (CC BY-NC 4.0) license, which permits others to distribute, remix, adapt, build upon this work non-commercially, and license their derivative works on different terms, provided the original work is properly cited, appropriate credit is given, any changes made indicated, and the use is non-commercial. See: http://creativecommons.org/licenses/by-nc/4.0/.

\section{REFERENCES}

1. Central Statistical Office (CSO), Ministry of Health (MOH), Tropical Diseases Research Centre (TDRC), University of Zambia, and Macro International Inc. Zambia demographic and health survey 2013-14. Calverton, Maryland, USA: CSO and Macro International Inc.

2. Siziya S, Rudatsikira E, Muula AS, et al. Predictors of cigarette smoking among adolescents in rural Zambia: results from a cross sectional study from Chongwe [corrected] district. Rural Remote Health 2007;7:728.

3. Brathwaite R, Addo J, Smeeth L, et al. A systematic review of tobacco smoking prevalence and description of tobacco control strategies in sub-Saharan African countries; 2007 to 2014. PLoS One 2015; 10:e0132401.

4. Siziya S. Higher prevalence rates of smoking in rural than urban areas among school-going adolescents in Lusaka Province, Zambia. Med J Zambia 2009;36.

5. Olowski P, Michelo C. Differential burden and determinants of tobacco smoking: population-based observations from the Zambia demographic and health survey (2002 and 2007). J Healthc Commun 2015;01:2472-1654.

6. Proctor MH, Moore LL, Singer MR, et al. Risk profiles for noncommunicable diseases in rural and urban schoolchildren in the Republic of Cameroon. Ethn Dis 1996:235-43.

7. Finau SA, Stanhope JM, Prior IA. Kava, alcohol and tobacco consumption among Tongans with urbanization. Soc Sci Med 1982;16:35-41.

8. Araújo C, Azevedo A, Damasceno A, et al. Evolving tobacco consumption in sub-Saharan Africa. Plos One 2015:153-6.

9. Pampel F. Tobacco use in sub-Sahara Africa: estimates from the demographic health surveys. Soc Sci Med 2008;66:1772-83.

10. Magitta Ng'weina Francis. Epidemiology of tobacco use and dependence in sub-Saharan Africa: a systematic review. Mbeya, Tanzania: Department of Biochemistry and Department of Clinical Pharmacology, Mbeya College of Health and Allied Sciences, University of Dar es Salaam, Journal of Pulmonology and Clinical Research (2018), 2018.

11. Sreeramareddy CT, Pradhan PM, Sin S. Prevalence, distribution, and social determinants of tobacco use in 30 sub-Saharan African countries. BMC Med 2014;12.

12. Dickson KS, Ahinkorah BO. Understanding tobacco use and socioeconomic inequalities among men in Ghana, and Lesotho. Arch Public Health 2017;75.

13. Sinha DN, Suliankatchi RA, Amarchand R, et al. Prevalence and sociodemographic determinants of any tobacco use and dual use in six countries of the who south-east Asia region: findings from the demographic and health surveys. NICTOB 2016;18:750-6.

14. Mamudu HM, John RM, Veeranki SP, et al. The odd man out in sub-Saharan Africa: understanding the tobacco use prevalence in Madagascar. BMC Public Health 2013;13:856.

15. Hsia J, Kaufmann R. Tobacco use by men and women in 49 countries with demographic and health surveys. DHS comparative reports No. 31. Calverton, Maryland, USA: ICF International, 2013.

16. Siziya S, Babaniyi O, Songolo P, et al. Prevalence and correlates for tobacco smoking among persons aged 25 years or older in Lusaka urban district, Zambia. J public health Epidemiol 2011;3:43-8.

17. Zyaambo C, Babaniyi O, Songolo $\mathrm{P}$, et al. Prevalence and predictors of cigarette smoking in a mining town in Kitwe, Zambia: a 2011 population-based survey. Health 2013;5:1021-5.

18. Mulenga D, Siziya S, Rudatsikira E, et al. District specific correlates for hypertension in Kaoma and Kasama rural districts of Zambia. Rural Remote Health 2013;13:2345.

19. Townsend J, Roderick P, Cooper J. Cigarette smoking by socioeconomic group, sex, and age: effects of price, income, and health publicity. BMJ 1994;309:923-7.

20. Blecher E, Ross H. Tobacco use in Africa. Tobacco Control through Prevention, American Cancer Society, 2013.

21. Jabbour S, Fouad FM. Religion-based tobacco control interventions: how should who proceed? Bull Worl Health Organ 2004;82.

22. Fakhfakh R, Hsairi M, Maalej M, et al. Tobacco use in Tunisia: behaviour and awareness. Bull Worl Health Organ 2002;80:350-6.

23. Chapman $\mathrm{S}$. The role of doctors in promoting smoking cessation. BMJ 1993;307:518-9.

24. Salawu FK, Danburum A, Desalu OO, et al. Cigarette smoking habits among adolescents in northwest Nigeria. Afri J of Resp Med 2009;8. 